\title{
Assessment of Social Participation in Three Measurement Times in Children with Traumatic Brain Injuries (TBI) Based on Parental Perceptions
}

\author{
Patrick Fougeyrollas ${ }^{1,2 \#, ~ C e ́ l i n e ~ L e p a g e 1,2, ~ L u c i e ~ B o i s s i e ̀ r e ' 1, ~ I s a b e l l e ~ D e a u d e l i n 1, ~}$ \\ Louis Doré ${ }^{*}$ \\ ${ }^{1}$ Rehabilitation Institute of Quebec City (IRDPQ), Quebec City, Canada \\ ${ }^{2}$ Centre for Interdisciplinary Research on Rehabilitation and Social Integration (CIRRIS), Quebec City, Canada \\ Email: "patrick.fougeyrollas@cirris.ulaval.ca
}

Received 10 August 2014; revised 12 September 2014; accepted 5 October 2014

Academic Editor: Takaya Narita, Department of Physical Therapy, Health Science University, Japan

Copyright (C) 2014 by authors and Scientific Research Publishing Inc.

This work is licensed under the Creative Commons Attribution International License (CC BY).

http://creativecommons.org/licenses/by/4.0/

(c) (i) Open Access

\begin{abstract}
Purpose: The aim of this study was to measure social participation in children with traumatic brain injuries (TBI) on their parental perceptions, retrospectively for the pre-injury period, at the beginning of rehabilitation and one year after return to school. Methods: This study was conducted among 17 children aged 5 to 17 years old with moderate or severe TBI and their parents. Social participation was assessed using the LIFE-H for Children (1.0). Results: A significant decrease $(p \leq 0.001)$ in the level of accomplishment of life habits was found for all categories between the measurements taken pre-injury and at the beginning of rehabilitation. Significant differences $(p \leq 0.002)$ related to the increase in the life habit accomplishment scores were also found between measurements taken at the beginning of rehabilitation and one year after return to school. Conclusion: TBI significantly affected the accomplishment of life habits of the participants compared to their pre-injury level. The assessment of social participation at various times provides a report on the client's progress and allows clinicians to update his or her intervention plan, to plan follow-ups or to end the intervention. This knowledge must be considered by anyone involved in helping these children to achieve their greatest social participation.
\end{abstract}

${ }^{*}$ Mr. Louis Doré deceased on 1st October 2014.

${ }^{*}$ Corresponding author. 


\section{Keywords}

\section{Traumatic Brain Injury, Social Participation, Life Habits, Children}

\section{Introduction}

There seems to be a broad consensus that social participation is the ultimate goal of the rehabilitation process [1]-[4]. In this study, we refer to the conceptual model of the Canadian Disability Creation Process (DCP). It provides a clear definition of the concept of social participation as being the result of the interaction between the individual and his/her environment [5]. In this concept, individuals are empowered to accomplish their life habits, which are the daily activities and social roles that are meaningful to them. In the Canadian classification, all life habits, even daily activities, are always understood as cultural constructs [6]-[9]. Although this social participation dimension is essential for anyone, it is crucial for children with physical disabilities because their development is uncompleted and sometimes jeopardised for those who acquire a TBI.

There has been a rapidly growing body of literature about the social participation of children with physical disabilities in the last decade [2]. Restrictions of participation have been reported in many studies, primarily in terms of education, recreation, community life, personal care, mobility, relationships with friends, as well as in outdoor and social activities [10]-[16]. Donkervoort et al. [17] also showed evidence that adolescents and young adults with cerebral palsy experience difficulties in the accomplishment of life habits related to daily activities (mobility, personal care and nutrition) as well as to their social roles (responsibilities, community life, recreation and employment). However, a great deal of variability was observed in their levels of participation [10] [13] [18]-[22].

In contrast, little research had specifically focused on children with traumatic brain injuries (TBI) in the beginning of this last decade, and the studies published have been mainly conducted by Bedell et al. [23]-[28]. Recently, more articles have been published and support their findings; Anaby et al., Foo et al., Law et al. [29]-[31] and a narrative review by Van Tol et al. [38]. According to these authors, children with TBI or Acquired Brain Injury (ABI) experience a lower level of participation. Foo's and Bedell's works showed that participation is specifically lower in community (and neighbourhood), school and home activities [28] [30]. Amongst Bedell's works, one study conducted among 60 children, adolescents and young adults (3 - 27 years of age), showed restrictions in social participation, mainly in structured community events and activities, social and play activities involving peers at school and in the community [28]. Less significant restrictions were observed in mobility at home, school, and in the community.

Furthermore, children with ABI have lower diversity and intensity of activities than typically-developing children [31]. In this study, Law et al. [31] comparing 135 children with ABI to 354 typically-developing peers demonstrated that children with $\mathrm{ABI}$ participated in fewer activities and less frequently except for intensity in social activities as measured by the Children Assessment of Participation and Enjoyment. These authors have observed that rates of participation in activities (diversity and intensity) tend to decline over time (over 1 year after return to school) [29]. However, brain injury could explain lower intensity observed in this group while the diversity of activities could be mainly influenced by children's preferences. In their review, Van Tol and collaborators reported same conclusions about participation of children with ABI. These children experience poorer adaptive functioning, have lower social competence, fewer friends and social activities [32].

The overall findings are generally consistent with those of studies conducted among populations of children with multiple physical disabilities. Mancini's study (2000) [33] $(n=341)$, including 13 children with TBI, also showed evidence that children and adolescents experience participation restrictions in school. Furthermore, two studies conducted among 124 young adults (aged 18 to 30) and 50 adults survivors (aged 19 to 30) who sustained a TBI during childhood or adolescence reported that the aspects related to education, employment, recreation and interpersonal relationships still affected them as adults [34] and those with more severe injuries were more likely to have educational and employment problems [35]. Rehabilitation interventions aimed at achieving the optimal level of social participation for children with TBI, at maintaining them in their own life environment and providing support to the community loom larger once the acute rehabilitation phase is completed. They focus on reducing the impact of difficulties and on enabling the child to reach their full potential. Moreover, the late onset of some complications related to skills that were not acquired or immature at the time of injury and the increase of environmental expectations and requirements support the relevance of monitoring 
the progress of children following rehabilitation [36].

The number of measurement tools specifically designed to assess participation in children is limited. Bedell and Coster [23] described four (4) measurement tools specifically designed for this purpose. They specified that people who are interested in conducting a thorough assessment of the various areas of participation should consider the use of the Assessment of Life Habits - Adapted to children (LIFE-H-Children). McConachie et al. and Morris et al., [37] [38] also concluded that this tool would be appropriate to assess participation in children. Based on the conceptual model of DCP, the LIFE-H is a valid and reliable measurement tool for the assessment of social participation [11] [39]. Additionally, some authors who reviewed ICF-based tools for measuring social participation concluded that the LIFE-H items are closely related to the social categories of the ICF's domains of participation [23] [37] [40] [41].

Although evidence shows that children with TBI face difficulties in social participation, and that valid and reliable tools are available to document their level of participation, few longitudinal studies were found. Only one study presents follow-up measures of participation levels with children sustaining ABI where data were collected three times over 1 year following return to school for 136 children with ABI [29]. None of the reviewed studies deals with the changes in their level of social participation overtime, whether by comparison with preinjury levels, with the exception of Donders and Ballard (1996) [42]. These authors used the Child Behavioral Checklist (CBC) to evaluate pre- and post-injury outcomes. However, this tool is not based on the conceptual models of social participation. Moreover, only few items on peer relationships, leisure time and school performance are included in the CBC.

The aim of this study was to measure the evolution of social participation in children with TBI retrospectively in pre-injury, at the beginning of their rehabilitation program and one year after return to school based on their parental perceptions. The research question was: which life habits will present moderate or severe restriction at the beginning of their rehabilitation program and one year after return to school.

\section{Method}

\subsection{Participants}

A convenience sample was formed following the approval of the study protocol by the Research Ethics Board of the Quebec City Rehabilitation Institute (Institut de réadaptation en déficience physique de Québec or IRDPQ). The participants of this study $(n=17)$ were children aged 5 to 17 years old with moderate or severe TBI benefiting from services provided by the IRDPQ's program for children with TBI (Table 1). The severity of TBI was based on the Glasgow Coma Scale.

\subsection{Material}

Social participation was assessed using the Assessment of Life Habits - Children (LIFE-H for Children 1.0) [43] which is recommended to thoroughly assess multiple domains of social participation [23] [37] [38]. This valid and reliable measurement tool presents psychometric properties that have been considered excellent (internal consistency: $0.82<$ ICC $<0.96$; intra-rater reliability: $\alpha>0.90$ ). This questionnaire documents the level of accomplishment of 64 life habits organized into twelve (12) categories (Table 2) [11] [39]. These cover a set of daily activities (e.g. eating meals, communication, mobility) and social roles (e.g. going to school, maintaining social relationships, taking part in recreational activities) typical of children according to their socio-cultural background. The Life-H is an outcome measure but this study cannot provide efficacy results because the independent variables related to the capacity, services and environment were not controlled.

The assessment is based on two concepts: the level of difficulty when performing a life habit and the type of

Table 1. Description of participants $(\mathrm{n}=17)$.

\begin{tabular}{ccccccc}
\hline \multirow{2}{*}{$\begin{array}{c}\text { Brain Injury } \\
\text { Severity }\end{array}$} & Age (Year) & Severity Level $^{\mathbf{a}}$ & \multicolumn{2}{c}{ Sex } & \multicolumn{2}{c}{ Education } \\
\cline { 2 - 6 } & Mean $( \pm$ SD) & Mean $( \pm$ SD) & Girlsn (\%) & Boysn (\%) & Primary School n (\%) & High School $\mathrm{n}(\%)$ \\
\hline Moderate $(\mathrm{n}=7)$ & $11.9 \pm 3.6$ & $10.4 \pm 1.9$ & $2(11.8)$ & $5(29.4)$ & $4(23.6)$ & $3(17.6)$ \\
Severe $(\mathrm{n}=10)$ & $12.3 \pm 3.2$ & $7.0 \pm 2.2$ & $3(17.6)$ & $7(41.2)$ & $3(17.6)$ & $7(41.2)$ \\
Total $(\mathrm{n}=17)$ & $12.1 \pm 3.2$ & $8.4 \pm 2.6$ & $5(29.4)$ & $12(70.6)$ & $7(41.2)$ & $10(58.8)$ \\
\hline
\end{tabular}

${ }^{\mathrm{a} B r a i n}$ Injury Severity as measured by the Glasgow Coma Scale: moderate (score between 9 and 12); severe (score between 3 and 8). 
Table 2. Number of items for each category of life habits.

\begin{tabular}{cccc}
\hline Daily Activities & \# of Items & Social Roles & \# of Items \\
\hline 1. Nutrition & 4 & 7. Responsibilities & 7 \\
2. Fitness & 4 & 8. InterpersonalRelationships & 6 \\
3. Personal Care & 8 & 9. Community Life & 2 \\
4. Communication & 8 & 10. Education & 6 \\
5. Housing & 6 & 11. Work & 8 \\
6. Mobility & 4 & 12. Recreation & 8 \\
\hline
\end{tabular}

assistance required (assistive device, adaptation and/or human assistance). An accomplishment rating scale on a continuum of ten levels ( 0 to 9 ) combines the two concepts. A score of 0 indicates that the individual is experiencing a full disabling situation (lack of the possibility to accomplish a particular life habit as the result of the individual/environment interaction), whereas a score of 9 points is the sign of an optimal level of social participation (life habit accomplished without difficulty or assistance). A standardized score between 0 and 10 can be established for each life habit category and for the overall tool (total score), taking into account only the items relevant to the child's life. To get the standardized score for each category, one does the sum of scores of each life habit multiplied by 10 and divided by the number of relevant life habits multiplied by 9 . To get the total score, one does the sum of standardized scores of each category divided by the number of relevant categories.

\subsection{Procedures}

The parents received information regarding the study from clinicians of IRDPQ's program for children with TBI. Those parents who wanted to participate were invited to sign an informed consent form. This study was approved by the Ethic Research Board of the Institut de réadaptation en déficience physique de Québec.

Data collection was carried out by an experienced clinician who received training in how to administer the measurement tool. He completed the interviews with the parents at the rehabilitation center or at parent's home according to their convenience. Parents were acting as proxies for information because children were too functionally impaired to complete a questionnaire at the beginning of the rehabilitation. The LIFE-H for children was administered for three measurements: retrospectively for the pre-injury period, at the beginning of rehabilitation and one year after return to school. The first testing session was conducted when the child arrived at the rehabilitation center. This session included the pre-injury and the beginning of rehabilitation data collections. For the pre-injury, where parents recalled retrospectively the participation status, there was 32 days ( \pm 23 days) between the injury and the first testing session. The return to school for the participants took place 7 months ( \pm 4 months) after the beginning of their rehabilitation interventions. The emphasis in the rehabilitation program at the Quebec City Rehabilitation Institute is usually on achieving the earliest possible return to school for the children, in order to facilitate the resuming of life habits in their usual settings, even if rehabilitation interventions need to be prolonged. The active process of rehabilitation is variable but usually completed after one year following their return to school.

The characteristics of the participants including the Glasgow Coma Scale were collected in the medical records.

\subsection{Data Analysis}

Descriptive analyses (i.e. median, percentile) were performed for the scores of each life habit category $(n=12)$ at each of the three measurement times. The accomplishment level was divided into three categories [44]; scores between 0 and 3 were identified as "severe restriction", scores between 4 and 7 as "moderate restriction" and scores of 8 and beyond as "no restriction", which also means a high level of social participation.

Nonparametric tests (Friedman's ANOVA, Wilcoxon Signed-Rank Test) were also performed in order to identify the presence or absence of significant changes in the accomplishment of life habits over time. The findings of two categories, community life and employment, could not be analyzed given the very small number of respondents for which these items were relevant. 


\section{Results}

\subsection{Pre-Injury Levels of Social Participation}

Approximately $25 \%$ of the participants reported that their child experienced moderate restrictions (scores between 4 and 7) (Figure 1). Pre-injury restrictions were observed for the life habits related to nutrition, communication, and education and more than $50 \%$ of the participants showed moderate restrictions with the responsibility items. Otherwise, for all other life habits that were analyzed, majority of participants reported no restriction for the accomplishment level of their child (scores between 8 and 10).

\subsection{Levels of Social Participation at the Beginning of the Rehabilitation}

On admission, all participants reported moderate or severe difficulties for their child in five categories: fitness, mobility, responsibilities, education, and recreation. For the other five categories: nutrition, personal care, communication, housing, and interpersonal relationships, more than three quarters of the participants reported that their child experienced moderate or severe difficulties (Figure 1).

\subsection{Levels of Social Participation One Year after Return to School}

For this time measurement, a majority of participants reported a high level of participation for their child in items related to nutrition, fitness, personal care, housing, interpersonal relationships, and recreation. In this case, however, many participants still reported their child having moderate difficulties, namely in items related to communication (31\%), mobility (50\%), responsibilities (50\%), and education (63\%) (Figure 1).

\subsection{Comparison between the Three Times of Measurement}

A significant decrease $(\mathrm{p} \leq 0.001)$ in the level of accomplishment of life habits was found for all categories between the measurements taken pre-injury and at the beginning of rehabilitation (Figure 1). On the other hand, significant differences $(\mathrm{p} \leq 0.002)$ related to the increase in the life habit accomplishment scores were found between measurements taken at the beginning of rehabilitation and one year after return to school (Figure 1). Also, significant differences were measured between pre-injury and one year after return to school scores in the mobility and education categories, where the scores were significantly lower one year after return to school (respectively, $\mathrm{p}=0.005$ and 0.034 ).

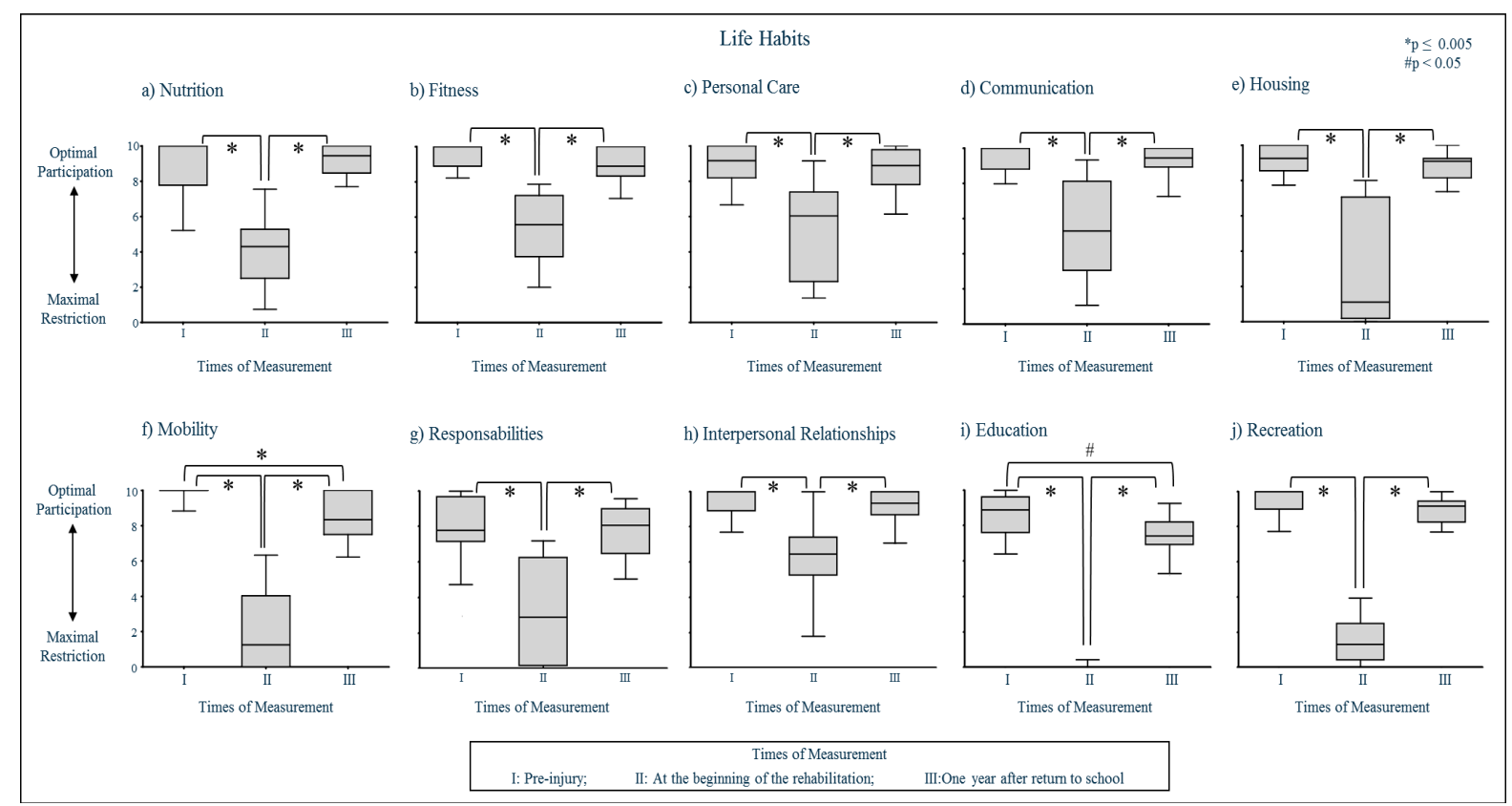

Figure 1. Levels of accomplishment of life habits of participants according to three times of measurement. 


\section{Discussion}

This article describes the level of social participation in children with TBI assessed by measuring their level of accomplishment of life habits in home, school and community settings retrospectively for the pre-injury period, at the beginning of rehabilitation and one year after return to school.

To our knowledge and according to Swaine (2012) [45], this study is the first to measure retrospectively pre-injury levels in all domains of social participation in children with TBI. This provided insight into pre-injury social participation. In fact, the findings reveal that approximately $25 \%$ of the participants were already experiencing restrictions in the accomplishment of some life habits, especially in categories such as nutrition, communication and education; and more than half of them in the accomplishment of responsibilities. Various factors might explain these findings. Based on their review of the literature, Max et al. (2004) [46] indicated that between $10 \%$ and $22 \%$ of children with TBI were also diagnosed with attention deficit disorders with hyperactivity prior to their injury. Woodward et al. (1999) [47] showed that $17 \%$ of children with TBI had learning disorders and $11 \%$ had emotional or behavior disorders. These rates are consistent with the information found in the participants' medical records, even though formal diagnoses for these disorders were lacking. Trauma and injury prevention are matters that should be studied further. Prevention programs should focus more on groups likely to sustain TBI.

Findings show that TBI significantly affected the accomplishment of life habits of the participants of this study. Subsequently, during the rehabilitation process and the return to school, children showed improvement in the level of accomplishment of all items. However, one year after return to school, difficulties were identified, especially with respect to items related to communication, mobility, responsibilities and education, in which difficulties remained for many participants. Additionally, for a small number of them, difficulties were still reported for items related to personal care and interpersonal relationships. This means that life habits categories related to participation at home, at school, and in the community are affected by TBI or physical disabilities [10]-[17] [24] [28] [31] [48]. Identified in all the reviewed studies as affecting participation of both children with TBI or physical disabilities, education was reported by the highest number of participants (75\%) as being the item in which many children experience difficulties. Education and interpersonal relationships are quite likely to be reported as the items with the most difficulties experienced in adulthood, as suggested by Anderson et al. [36] in a study conducted among 124 young adults who sustained TBI during their childhood or adolescence. Also, Sirois et al. (2014) [49] showed that adolescents and young adults think that they will always experience difficulties in the accomplishment of items related to education in the future. Similarly, interpersonal relationships are a major concern for them as they identified the need to maintain good family relationships. Given the importance of education for primary and secondary school-aged children, and the dominance of interpersonal relationships in all aspects of their life, difficulties in these life habits could have a major impact on their quality of life and that of their family.

Furthermore, present findings were not similar to those published in earlier studies. In fact, half of the participants in this study reported that they were still experiencing difficulties in mobility one year after return to school. While Bedell and Dumas (2004) [28] found that the less significant restrictions of participation of their population of 60 children, adolescents and young adults were generally observed in mobility. However, some of their participants were diagnosed with conditions other than TBI, and since their findings were not specific to people with TBI, they cannot be fully compared with the current findings. Also, the measurement tool they used was comprised of only one mobility-related item, which may have masked the presence of difficulties in this category. Mobility-related items assessed in the LIFE-H, such as the mobility in community item "Moving around on streets and sidewalks including crossing streets”, not only require motor skills, but also cognitive and various other skills. Clinical evidence shows that mobility-related difficulties may be caused by limitations in the ability to orient oneself, fear of traffic, and parental overprotection.

Recreation was identified as presenting restrictions in all of the reviewed studies in children with TBI except for intensity in social activities [31]. However, present results did not support these findings. Participants actually reported a very low level of participation for the recreation category on admission, and although they did not recover their pre-injury level of participation one year after return to school, there were no significant differences between the pre-injury and one year after return to school scores. Discrepancies between the present findings and those of previous studies may be partly accounted for by absence of a comparison with pre-injury participation levels in the previous studies and the different measurement tools. For the latter point, it is possible 
that different tools have different sensitivities for a given life habit category. The clinical experience shows that children with TBI have very little leisure time in the long term and often become quite isolated. Future studies with a larger number of participants than in previous studies could help to give more information about recreation.

No control group was used in the present study and few data are available in the literature on the participation levels of children without disability. The first data gathered in the general population were from a study on children with Developmental Coordination Disorder (DCD) ( $\mathrm{n}=27,5$ to 13 years old) and the group of comparison composed with 27 children (5 to 12 years old) with typical development [50]. Findings showed that group participants with typical development have experienced full accomplishment of their life habits as assessed by the LIFE-H for Children. Although these participants had no restriction, scores of responsibility, fitness and personal care categories showed the most variability. It could be assumed that a comparison group of typically developed children from 5 to 18 years of age would not have experienced difficulties in the accomplishment of their life habits. Law et al. [31] have described and compared the participation patterns of children and youth with $(\mathrm{n}=135)$ and without ABI $(\mathrm{n}=354)$. The relative proportion of participation diversity in activities of both groups has presented a similar trend: physical and skill-based activities are less frequent than recreational, social and self-improvement activity types. Although children with ABI were engaged in similar activities than typically-developing peers, they presented a lower level of participation. Problems related to ABI could explain they avoid some kind of activities like physical and skill-based activities and should be considered in rehabilitation program. In fact, activities involving fewer rules and structures (e.g. talking on the phone, listening to music) could be easier to children with ABI.

One of the main limitations of the study was the small number of participants, which prevented from generalizing the findings to the rest of the population.

Also, despite the intent to document the perception of participants aged 10 years and older, which is considered clinically valid for the LIFE-H, it was impossible because children were too functionally impaired to complete a questionnaire at the beginning of the rehabilitation. But, parents could have different perspectives than the children. However, according to Young et al. (1995) [15], there should not be significant differences between parental answers and those of their children with regard to their physical disabilities. More specifically, Prigatano and Gray (2008) [52] showed that the parental perspective related to the recovery and reintegration of their child or adolescent with TBI into society ( $n=80,6$ to 16 years old) indicated a good validity. Erhart et al. (2009) have reported similar findings and have concluded that proxies reports provided slightly higher reliability and thus are favoured for the assessment of small samples [53]. Furthermore, the recall of parents, for the preinjury information, could have been viewed in light of the experienced trauma. Another limitation is due to the fact of no functional or environmental variables were controlled during the study, so, the results could not be attributed to the efficacy of the rehabilitation interventions.

\section{Conclusion and Clinical Impact}

The results of this study show that children and adolescents improve their level of social participation during the rehabilitation process. However, some of them still experience difficulties regarding the education and mobility categories and require to be supported on a long term in their social participation. In fact, despite their recovery, the presence of difficulties in the accomplishment of life habits highlights the importance of providing long-term support in the aspects that are affected.

The assessment of social participation using the LIFE-H for children has led to the standardization of its use for clients in IRDPQ's program for children and adolescents with TBI. When possible, taking into account both perceptions of clients and of their family, these data are used, to identify interdisciplinary rehabilitation goals and plan interventions which, before, were more capacity oriented. The LIFE-H can be used as measure of progress in social participation during rehabilitation, which can lead to more effective interventions aimed at supporting children and adolescents in achieving their optimal level of social participation. In addition, the use of the LIFE-H facilitates the long-term follow-up of clients in order to screen those who require additional support. It would be interesting to conduct a similar study with a larger group of participants.

\section{Acknowledgements}

This study was sponsored by the Fondation Élan of the IRDPQ. The authors would like to thank all clinicians, parents, children and adolescents who contributed to this study. Special thanks to Désirée Maltais Ph.D. for her 
very helpful linguistic review and comments.

\section{Conflicts of Interest}

Authors declare no conflicts of interest.

\section{References}

[1] Coster, W. and Alunkal-Khetani, M. (2008) Measuring Participation of Children with Disabilities: Issues and Challenges. Disability and Rehabilitation, 30, 639-648.

[2] Imms, C. (2008) Children with Cerebral Palsy Participate: A Review of the Literature. Disability and Rehabilitation, 30, 1867-1884. http://dx.doi.org/10.1080/09638280701673542

[3] Law, M. (2002) Enhancing Participation. Physical \& Occupational Therapy in Pediatrics, 22, 103. http://dx.doi.org/10.1080/J006v22n01 01

[4] Simeonsson, R.J., Carlson, D., Huntington, G.S., Sturtz-McLillen, J. and Lytle-Brent, J. (2001) Students with Disabilities: ANational Survey of Participation in School Activities. Disability and Rehabilitation, 23, 49-63. http://dx.doi.org/10.1080/096382801750058134

[5] Fougeyrollas, P., Cloutier, R., Bergeron, H., Côté, J. and St-Michel, G. (1999) Quebec Classification: Disability Creation Process. International Network on Disability Creation Process - Canadian Society on International Classification of Impairments, Disabilities and Handicaps, INDCP/CSICIDH, Quebec City.

[6] Ravaud, J.F. and Fougeyrollas, P. (2005) Le concept de handicap et les classifications internationale. La convergence progressive des positions franco-québécoises. Santé, Solidarité et Société, 25, 121-127.

[7] Noonan, V.K., et al. (2009) Comparing the Content of Participation Instruments Using the International Classification of Functioning, Disability and Health. Healthand Quality of Life Outcomes, 7, 93. http://dx.doi.org/10.1186/1477-7525-7-93

[8] Fougeyrollas, P. (2010) La funambule, le fil et la toile. Transformations réciproques du sens du handicap. Collection Sociétés, cultures et santé. Les Presses de l’Université Laval, Quebec City.

[9] Fougeyrollas, P. (2012) Social Participation. In: Stone, J.H. and Blouin, M., Eds. International Encyclopedia of Rehabilitation, University of Buffalo, Buffalo, 9 pp. http://cirrie.buffalo.edu/encyclopedia/pdf/en/social participation.pdf

[10] Lepage, C., Noreau, L., Bernard, M.P. and Fougeyrollas, P. (1998) Profile of Handicap Situations in Children with Cerebral Palsy. Scandinavian Journal of Rehabilitation Medicine, 30, 263-272. http://dx.doi.org/10.1080/003655098444011

[11] Noreau, L., Lepage, C., Boissiere, L., Picard, R., Fougeyrollas, P., Mathieu, J., et al. (2007) Measuring Participation in Children with Disabilities Using the Assessment of Life Habits. Developmental Medicine and Child Neurology, 49, 666-671. http://dx.doi.org/10.1111/j.1469-8749.2007.00666.x

[12] Chan, H.S.S., Lau, P.H.B., Fong, K.H., Poon, D. and Lam, C.C.C. (2005) Neuroimpairment, Activity Limitation, and Participation Restriction among Children with Cerebral Palsy in Hong Kong. Hong Kong Medical Journal, 11, 342350.

[13] Erikson, L., Welander, J. and Granlund, M. (2007) Participation in Everyday School Activities for Children with and without Disabilities. Journal of Developmental and Physical Disabilities, 19, 485-502. http://dx.doi.org/10.1007/s10882-007-9065-5

[14] Schenker, R., Coster, W. and Parush, S. (2005) Participation and Activity Performance of Students with Cerebral Palsy within the School Environment. Disability and Rehabilitation, 27, 539-552. http://dx.doi.org/10.1080/09638280400018437

[15] Shikako-Thomas, K., Majnemer, A., Law, M. and Lach, L. (2008) Determinants of Participation in Leisure Activities in Children and Youth with Cerebral Palsy: Systematic Review. Physical \& Occupational Therapy in Pediatrics, 28, 155-169. http://dx.doi.org/10.1080/01942630802031834

[16] Parkes, J., McCullough, N. and Madden, A. (2010) To What Extent Do Children with Cerebral Palsy Participate in Everyday Life Situations? Health \& Social Care in the Community, 18, 304-315.

[17] Donkervoort, M., Roebroeck, M., Wiegerink, D., van der Heijden-Maessen, H., Stam, H., et al. (2007) Determinants of Functioning of Adolescents and Young Adults with Cerebral Palsy. Disability and Rehabilitation, 29, 453-463. http://dx.doi.org/10.1080/09638280600836018

[18] Imms, C., Reilly, S., Carlin, J. and Dodd, K. (2008) Diversity of Participation in Children with Cerebral Palsy. Developmental Medicine and Child Neurology, 50, 363-369. http://dx.doi.org/10.1016/j.ejpn.2008.03.005

[19] Michelsen, S.I., Flachs, E.M., Uldall, P., Eriksen, E.L., McManus, V., Parkes, J., et al. (2009) Frequency of Participa- 
tion of 8-12-Year-Old Children with Cerebral Palsy: A Multi-Centre Cross-Sectional European Study. European Journal of Paediatric Neurology, 13, 165-177. http://dx.doi.org/10.1016/j.ejpn.2008.03.005

[20] Law, M., King, G., King, S., Kertoy, M., Hurley, P., Rosenbaum, P., et al. (2006) Patterns of Participation in Recreational and Leisure Activities among Children with Complex Physical Disabilities. Developmental Medicine and Child Neurology, 48, 337-342. http://dx.doi.org/10.1017/S0012162206000740

[21] Morris, C., Kurinczuk, J.J., Fitzpatrick, R. and Rosenbaum, P.L. (2006) Do the Abilities of Children with Cerebral Palsy Explain Their Activities and Participation? Developmental Medicine and Child Neurology, 48, 954-961.

[22] Kerr, C., McDowell, B. and McDonough, S. (2006) The Relationship Between Gross Motor Function and Participation Restriction in Children with Cerebral Palsy: An Exploratory Analysis. Child: Care, Health and Development, 33, 2227. http://dx.doi.org/10.1111/j.1365-2214.2006.00634.x

[23] Bedell, G. and Coster, W. (2008) Measuring Participation of School-Aged Children with Traumatic Brain Injuries: Considerations and Approaches. Journal of Head Trauma Rehabilitation, 23, 220-229. http://dx.doi.org/10.1097/01.HTR.0000327254.61751.e7

[24] Bedell, M.G., Haley, M.S., Coster, J.W. and Smith, W.K. (2002) Participation Readiness at Discharge from Inpatient Rehabilitation in Children and Adolescents with Acquired Brain Injuries. Pediatric Rehabilitation, 5, 102-116.

[25] Bedell, M.G. (2004) Developing a Follow-Up Survey Focused on Participation of Children and Youth with Acquired Brain Injuries After Discharge from Inpatient Rehabilitation. NeuroRehabilitation, 19, 191-205.

[26] Bedell, M.G., Cohn, E.S. and Dumas, H.M. (2005) Exploring Parents' Use of Strategies to Promote Social Participation of School-Age Children with Acquired Brain Injuries. American Journal of Occupational Therapy, 59, $273-284$. http://dx.doi.org/10.5014/ajot.59.3.273

[27] Dumas, H.M., Bedell, G.M. and Shannon-Hamill, M. (2003) Strategies to Promote Activity and Participation in Children and Youths with Acquired Brain Injuries. International Journal of Rehabilitation Research, 26, 303-308. http://dx.doi.org/10.1097/00004356-200312000-00008

[28] Bedell, M.G. and Dumas, H.M. (2004) Social Participation of Children and Youth with Acquired Brain Injuries Discharged from Inpatient Rehabilitation: A Follow-Up Study. Brain Injury, 18, 65-82. http://dx.doi.org/10.1080/0269905031000110517

[29] Anaby, D., Law, M., Steven, H. and Dematteo, C. (2012) Predictors of Change in Participation Rates Following Acquired Brain Injury: Results of a Longitudinal Study. Developmental Medicine and Child Neurology, 54, 339-346. http://dx.doi.org/10.1111/j.1469-8749.2011.04204.x

[30] Foo, W.S., Galvin, J. and Olsen, J. (2012) Participation of Children with ABI and the Relationship with Discharge Functional Status. Developmental Neurorehabilitation, 15, 1-12. http://dx.doi.org/10.3109/17518423.2011.623142

[31] Law, M., Anaby, D., Dematteo, C. and Hanna, S. (2011) Participation Patterns of Children with Acquired Brain Injury. Brain Injury, 25, 587-595. http://dx.doi.org/10.3109/02699052.2011.572945

[32] Van Tol, E., Gorter, J.W., DeMatteo, C. and Meester-Delver, A. (2011) Participation Outcomes for Children with Acquired Brain Injury: A Narrative Review. Brain Injury, 25, 1279-1287. http://dx.doi.org/10.3109/02699052.2011.613089

[33] Mancini, M.C., Coster, W.J., Trombly, C.A. and Heeren, T.C. (2000) Predicting Elementary School Participation in Children with Disabilities. Archives of Physical Medicine and Rehabilitation, 81, 339-347. http://dx.doi.org/10.1016/S0003-9993(00)90081-9

[34] Anderson, V., Brown, S., Newitt, H. and Hoile, H. (2009) Educational, Vocational, Psychosocial, and Quality-of-Life Outcomes for Adult Survivors of Childhood Traumatic Brain Injury. Journal of Head Trauma Rehabilitation, 24, 303312. http://dx.doi.org/10.1097/HTR.0b013e3181ada830

[35] Anderson, V., Brown, S., Newitt, H. and Hoile, H. (2011) Long-Term Outcome from Childhood Traumatic Brain Injury: Intellectual Ability, Personality, and Quality of Life. Neuropsychology, 25, 176-184. http://dx.doi.org/10.1037/a0021217

[36] Anderson, V.A., Catroppa, C., Dudgeon, P., Morse, S.A., Haritou, F. and Rosenfeld, J.V. (2006) Understanding Predictors of Functional Recovery and Outcome 30 Months Following Early Childhood Head Injury. Neuropsychology, 20, 42-57. http://dx.doi.org/10.1037/0894-4105.20.1.42

[37] McConachie, H., Colver, A.F., Forsyth, R.J., Jarvis, S.N. and Parkinson, K.N. (2006) Participation of Disabled Children: How Should It Be Characterised and Measured? Developmental Medicine and Child Neurology, 28, 1157-1164.

[38] Morris, C., Kurinczuk, J.J. and Fitzpatrick, R. (2005) Child or Family Assessed Measures of Activity Performance and Participation for Children with Cerebral Palsy: A Structured Review. Child: Care, Health and Development, 31, 397407. http://dx.doi.org/10.1111/j.1365-2214.2005.00519.x

[39] Noreau, L., Fougeyrollas, P. and Vincent, C. (2002) The LIFE-H: Assessment of the Quality of Social Participation. 
Technology and Disability, 14, 113-118.

[40] Sakzewski, L., Boyd, R. and Ziviany, J. (2007) Clinimetric Properties of Participation Measures for 5-13-Year-Old Children with Cerebral Palsy: A Systematic Review. Developmental Medicine and Child Neurology, 48, $232-240$. http://dx.doi.org/10.1111/j.1469-8749.2007.00232.x

[41] Resnik, L. and Plow, M.A. (2009) Measuring Participation as Defined by the International Classification of Functioning, Disability and Health: An Evaluation of Existing Measures. Scandinavian Journal of Rehabilitation Medicine, 90, 856-866.

[42] Donders, J. and Ballard, E. (1996) Psychological Adjustment Characteristics of Children before and after Moderate to Severe Traumatic Brain Injury. Journal of Head Trauma Rehabilitation, 11, 67-73. http://dx.doi.org/10.1097/00001199-199606000-00010

[43] Fougeyrollas, P., et al. (2003) Assessment of Life Habits (LIFE-H for Children 5-13, 1.0) Adapted for Children 5 to 13 years, Short Form (French Version). International Network for Disability Creation Process, INDCP, RIPPH/SCCIDIH, Quebec City.

[44] Boucher, N., Dumas, F., Maltais, D.M. and Richards, C.L. (2010) The Influence of Selected Personal and Environmental Factors on Leisure Activities in Adults with Cerebral Palsy. Disability \& Rehabilitation, 32, 1328-1338. http://dx.doi.org/10.1111/j.1469-8749.2011.04210.x

[45] Swaine, B. (2012) Participation Following Pediatric Acquired Brain Injury and Some Inherent Problems with Outcome Studies. Developmental Medicine and Child Neurology, 54, 296-297. http://dx.doi.org/10.1111/j.1469-8749.2011.04210.x

[46] Max, E.J., Lansing, A.E., Koele, S.L., Castillo, C.S., Bokura, H., Schachar, R., et al. (2004) Attention Deficit Hyperactivity Disorder in Children and Adolescents Following Traumatic Brain Injury. Developmental Neuropsycholology, 25, 159-177.

[47] Woodward, H., Winterhalther, K., Donders, J., Hackbarth, R., Kuldanek, A. and Sanfilippo, D. (1999) Prediction of Neurobehavioral Outcome 1-5 Years Post Pediatric Traumatic Head Injury. Journal of Head Traumatic Rehabilitation, 14, 351-359. http://dx.doi.org/10.1097/00001199-199908000-00004

[48] Jaffe, M.K., Lincoln-Polissar, N., Fay, C.G. and Liao, S. (1995) Recovery Trends over Three Years Following Pediatric Traumatic Brain Injury. Archives of Physical Medicine and Rehabilitation, 76, 17-26. http://dx.doi.org/10.1016/S0003-9993(95)80037-9

[49] Katia, S., Normand, B. and Céline, L. (2014) Current Needs, the Future of Adolescents and Young Adults Having Sustained a Moderate or Severe Traumatic Brain Injury (TBI) and the Potential of Their Social Participation. Open Journal of Therapy and Rehabilitation, 2, 45-55. http://dx.doi.org/10.4236/ojtr.2014.21009

[50] Sylvestre, A., Nadeau, L., Charron, L., Larose, N. and Lepage, C. (2013) Social Participation by Children with Developmental Coordination Disorder Compared to Their Peers. Disability \& Rehabilitation, 35, 1814-1820. http://dx.doi.org/10.3109/09638288.2012.756943

[51] Young, N.L., Yoshida, K.K., Williams, J.I., Bombardier, C. and Wright, J.G. (1995) The Role of Children in Reporting Their Physical Disability. Archives of Physical Medicine and Rehabilitation, 76, 913-918. http://dx.doi.org/10.1016/S0003-9993(95)80066-2

[52] Prigatano, P.G. and Gray, J. (2008) Parental Perspectives on Recovery and Social Reintegration after Pediatric Traumatic Brain Injury. Journal of Head Trauma Rehabililitation, 23, 378-387. http://dx.doi.org/10.1097/01.HTR.0000341433.67251.01

[53] Erhart, M., Ellert, U., Kurth, B.M. and Ravens-Sieberer, U. (2009) Measuring Adolescents’ HRQoL via Self Reports and Parent Proxy Reports: An Evaluation of the Psychometric Properties of both Versions of the KINDL-R Instrument. Health and Quality of Life Outcomes, 7, 77. http://dx.doi.org/10.1186/1477-7525-7-77 
Scientific Research Publishing (SCIRP) is one of the largest Open Access journal publishers. It is currently publishing more than 200 open access, online, peer-reviewed journals covering a wide range of academic disciplines. SCIRP serves the worldwide academic communities and contributes to the progress and application of science with its publication.

Other selected journals from SCIRP are listed as below. Submit your manuscript to us via either submit@scirp.org or Online Submission Portal.
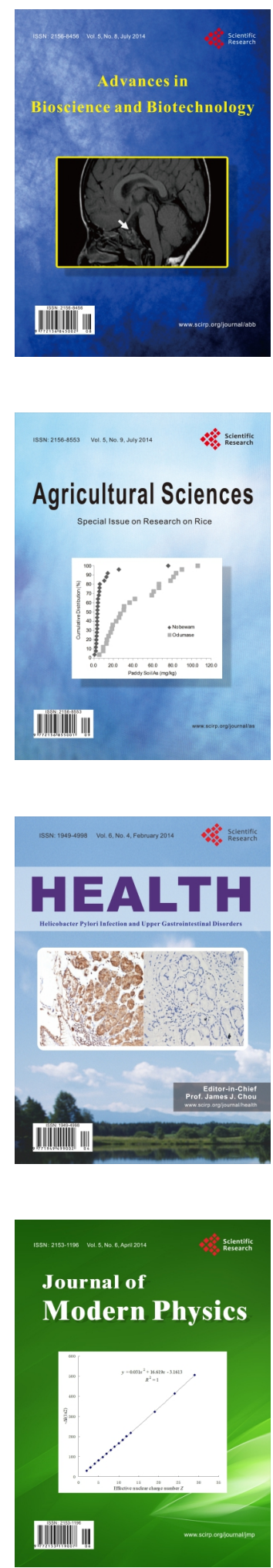
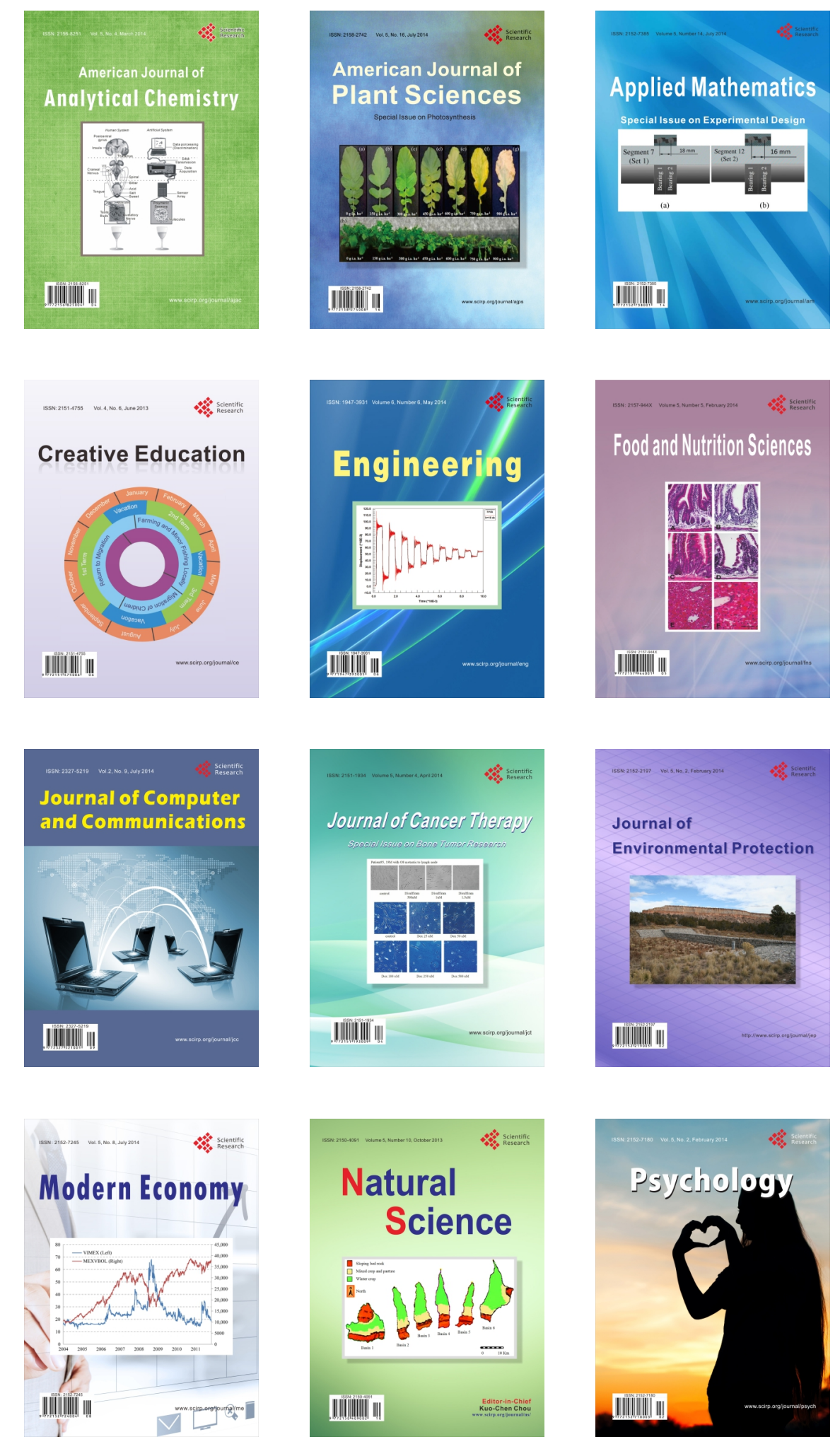